\title{
KONDISI SOSIAL EKONOMI MASYARAKAT NELAYAN DI DESA TATELI DUA KECAMATAN MANDOLANG KABUPATEN MINAHASA PROVINSI SULAWESI UTARA
}

\author{
Hendrikus K. Erakapia'; Grace O. Tambani2; Jeannette F. Pangemanan² \\ 1)Mahasiswa Fakultas Perikanan dan IImu Kelautan Universitas Sam Ratulangi Manado \\ 2)Staff Pengajar Fakultas Perikanan dan IImu Kelautan Universitas Sam Ratulangi Manado \\ Koresponden email :hendrikuserakipia@gmail.com
}

\begin{abstract}
The purpose of this study was to reveal and assess the socio-economic conditions of fishing communities in Tateli Dua Village, Mandolang District.

The method used in this study is descriptive method, sampling using random sampling technique. There were 20 respondents who worked as fishermen.

The social conditions of the fishermen of Tateli Dua Village in terms of education are mostly elementary school education, there are 2 respondent religions, namely Islam and Protestant Christianity, the age of fishermen is in the productive age range of 7 people, most respondents have experienced pain with medical treatment and use traditional medicine family dependents ranged between 2-7 and from housing owned by most (50\%) respondents had semi-permanent housing types.

The economic conditions of the fishermen in Tateli Dua Village are from business capital, almost all (95\%) of respondents use their own capital. Most of the marketing places for the catch are in the market with the highest income of the respondents being Rp. 500,000 - Rp. 1,000,000. The work of respondents other than fishermen partly has a side job as a builder with an income of $R p .500,000$ - Rp. 1,000,000 and the respondent's expenditure ranges from Rp. 500,000 - Rp. 1,000,000.
\end{abstract}

Keywords: socio-economic, fisherman, Tateli Dua Village

\section{Abstrak}

Tujuan penelitian ini adalah untuk mengungkapkan dan mengkaji kondisi sosial ekonomi masyarakat nelayan di Desa Tateli DuaKecamatan Mandolang.

Metode yang digunakan dalam penelitian ini adalah metode deskriptif, pengambilan sampel menggunakan teknik random sampling. Responden berjumlah 20 orang yang berprofesi sebagai nelayan.

Kondisi sosial nelayan Desa Tateli Dua dari segi pendidikan paling banyak berpendidikan SD, terdapat 2 agama responden yaitu Islam dan Kristen Protestan, umur nelayan berada pada kisaran umur produktiv sebanyak 7 orang, sebagian besar responden pernah mengalami sakit dengan tempat berobat ke Puskesmas dan memakai obat tradisional, tanggungan keluarga berkisar antara 2 - 7 dan dari perumahan yang dimiliki sebagian besar $(50 \%)$ responden memiliki jenis rumah semi permanen.

Kondisi ekonomi nelayan Desa Tateli Dua dari modal usaha, hampir seluruh (95\%) responden menggunakan modal sendiri.Tempat pemasaran hasil tangkapan sebagian besar di pasar dengan pendapatan responden paling tinggi adalah $\mathrm{Rp} 500.000$ - Rp 1.000.000.Pekerjaan responden selain nelayan sebagian memiliki pekerjaan sampingan sebagai tukang bangunan dengan pendapatan Rp 500.000 - Rp 1.000 .000 dan tingkat pengeluaran responden berkisar antaraRp 500.000 - Rp 1.000.000.

Kata kunci: sosial ekonomi, nelayan, Desa Tateli Dua

\section{PENDAHULUAN}

Kehidupan masyarakat nelayan merupakan suatu keadaan nyata dapat diungkapkan melalui usaha mereka yang dipengaruhi oleh musim penangkapan ikan, kondisi alam, tingkat pendidikan yang masih rendah, penggunaan alat tangkap yang masih tradisional dan kendala ekonomi seperti terbatasnya modal sehingga usaha tidak dapat berkembang, serta transportasi yang tidak menunjang dan kelembagaan ekonomi yang tidak mendukung sehingga posisi nelayan dalam penentuan hasil tangkap dan pemasaran sangat kurang.

Kondisi seperti ini tidak lepas dari masalah-masalah pembangunan karena, dipengaruhi oleh berbagai aspek sosial ekonomi yang masih kurang dimengerti oleh nelayan bahkan, ada yang tidak 
tahu sehingga sangat berpengaruh terhadap kehidupan masyarakat nelayan di pedesaan, sehubungan dengan ini maka pembangunan perikanan harus dilakukan dengan cara pendekatan sosial ekonomi.

Dinas Kelauatan dan Perikanan (DKP) Sulawesi Utara saat ini mencatat ada 33.943 nelayan yang tersebar di 13 kabupaten/kota. Secara khusus di Kabupaten Minahasa pada tahun 2017 mencapai 9.173 orang nelayan, dimana jumlah ini terdiri atas 4.672 orang nelayan penuh, 2.125 orang nelayan sambilan utama dan sisanya 2.376 orang adalah nelayan sambilan tambahan (Dinas Kelautan dan Perikanan Kabupaten Minahasa, 2017). Kondisi sosial ekonomi masyarakat nelayan atau masyarakat pesisir merupakan kelompok masyarakat yang relatif tertinggal secara sosial dan ekonomi dibandingkan dengan kelompok masyarakat lain. Kondisi masyarakat nelayan atau masyarakat pesisir diberbagai kawasan pada umumnya ditandai oleh adanya beberapa ciri, seperti kemiskinan, keterbelakangan sosial-budaya, rendahnya sumberdaya manusia.sehingga pada saat ini dapat dilihat bahwa sebagian besar masyarakat pesisir masih berada di bawah garis kemiskinan (Nawawi, 2014).

Data di atas mencatat bahwa bukan sedikit yang berstatus nelayan baik nelayan penuh, atau nelayan sambilan utama dan nelayan sambilan tambahan, karena dari angka-angka ini menggambarkan bahwa 27,03\% nelayan berkedudukan di Kabupaten Minahasa.

Desa Tateli Dua merupakan salah satu Desa yang berada di Kecamatan Mandolang Kabupaten Minahasa, di mana masyarakat umumnya bermata pencarian sebagai nelayan.Selama ini, secara kasad mata kelihatan bahwa nelayan di Desa ini sudah turun-temurun melakukan pekerjaan ini dan sampai sekarang mereka tetap mereka menekuni kegiatan penangkapan ikan di laut, dengan sangat rajin melakukannya oleh karena keterampilan menangkap ikan diturunkan dari kakek atau orang tuanya secara langsung. Mereka merasa senang melakukan kegiatan ini karena hasil yang didapat cukup untuk kehidupan mereka keluarga (Manoppo, 2013)

Keberadaan nelayan Desa Tateli Dua sampai saat ini belum layak ditemukan baik berupa tulisan-tulisan ilmiah maupun penelitian-penelitian serta bacaan-bacaan berbentuk artikel dan lain sebagainya sehingga sangat dibutuhkan untuk di Teliti Dua agar supaya boleh menambah kesan tulisan ilmiah seperti desa-desa nelayan lainnya yang ada di Kabupaten Minahasa.

\section{METODE PENELITIAN}

Metode penelitian adalah deskriptif, di mana penelitian bersifat deskriptif merupakan penelitian yang bertujuan untuk mengungkapkan suatu kenyataan sosial dengan jalan mendeskripsikan secara tepat sifat-sifat individu, keadaan, gejala, kelompok tertentu berkenaan dengan masalah unit yang diteliti dalam masyarakat (Faisal, 2003).

Responden dalam penelitian ini adalah neleyan penangkap ikan di Desa Tateli Dua Kecamatan Mandolang Kabupaten Minahasa.Sampel diambil sebesar $50 \%$ atau sebanyak 20 orang dengan menggunakan metode pengambilan secara acak sederhana atau simple random sampling.

Teknik pengumpulan data dalam penelitian ini dengan menggunakan:

1. Kuesioner atau daftar pertanyaan 
Metode ini digunakan untuk mencari data primer untuk pengumpulan data tentang usaha perahu "tambangan"/ojek perahu dan kontribusinya terhadap pendapatan rumah tangga.

2. Wawancara

Metode ini dilakukan pada saat melakukan pengumpulan data untuk mendapatkan data yang diperlukan peneliti untuk menjawab rumusan masalah penelitian.

Analisis yang akan digunakan dalam penelitian ini adalah analisis deskriptif kuantitatif merupakan pengolahan data dengan menggunakan perhitungan matematis sederhana seperti penjumlahan, pengurangan, perkalian, angka rata-rata dan persentase (\%). Sedangkan analisis deskriptif kualitatif adalah pengolahan data yang dilakukan melalui pertimbangan-pertimbangan

logikadengan bahasa-bahasa penulis yang sistematis.Data yang telah dianalisis kemudian diinterpretasikan dengan pertimbangan-pertimbangan logika yang menggunakan bahasabahasa penulis yang sistematis dengan mengacu pada referensi yang berkaitan dengan hasil-hasil penelitian, jurnaljurnal dan arahan dari Pembimbing (Fathoni, 2006).

\section{HASIL DAN PEMBAHASAN}

\section{Kondisi Sosial Responden di Desa Tateli Dua \\ Pendidikan}

Kehidupan masyarakat yang tinggal di daerah pesisir tidak begitu baik dilihat dari tingkat pendidikan dan ekonominya yang ada.Masyarakat nelayan pada umumnya belum begitu memperhatikan kondisi pendidikan sampai sekarang tetapi sebenarnya pendidikan merupakan salah satu aspek menyangkut kondisi sosial.Aspek pernyataan umum tentang pendidikan berkaitan di tempat penelitian.Untuk lebih jelasnya dapat dilihat pada masyarakat nelayan yang menjadi responden pada tabel di bawah ini.

Tabel 2. Jumlah Responden Berdasarkan Tingkat Pendidikan

\begin{tabular}{|c|l|c|c|}
\hline No. & \multicolumn{1}{|c|}{ Pendidikan } & Jumlah & $(\%)$ \\
\hline 1. & SD & 8 & 40 \\
\hline 2. & SLTP & 6 & 30 \\
\hline 3. & SLTA & 6 & 30 \\
\hline \multicolumn{2}{|c|}{ Jumlah } & 20 & 100 \\
\hline
\end{tabular}

Sumber : Hasil Pengolahan Data Primer, 2018

Hasil penelitian menunjukan bahwa nelayan yang ada di Desa Tateli Dua yang menempuh pendidikan paling tinggi yaitu sekolah lanjutan tingkat atas (SLTA) berjumlah 6 orang (30\%) saja.Tingkat pendidikan Sekolah Lanjutan Pertama (SLTP) sebesar 30\% juga, sedangkan tingkat pendikan Sekolah Dasar sebesar 40\%. Berdasarkan hasil analisis ini maka tingkat pendidikan yang ada di desa ini dapat dikatakana baik karena semua responden umumnya telah memenuhi keinginan pemerintah untuk duduk dalam bangku sekolah sehingga tindak ada lagi yang buta huruf, bahkan $60 \%$ dari responden sudah memiliki status pendidikan lebih tinggi yaitu SLTP dan SLTA.

\section{Agama}

Hasil penelitian menunjukan bahwa nelayan yang ada di desa ini ternyata memiliki dua agama yang dianutnya yaitu Agama Islam sebesar 85\% dan Agama Kristen Protestan sebesar $15 \%$ saja. Data yang ada menggambarkan bahwa untuk aspek agama ternyata nelayan responden di desa ini pada umumnya sudah baik karena, semua responden mempunyai 
keyakinan yang dianut dan tidak seorang pun yang tidak mempunyai keyakinan.

Keberadaan nelayan yang ada di desa ini dapat dibuktikan dengan sarana peribadatan yang ada karena saran peribadatan itu merupakan suatu dasar bahwa nelayan responden sangat memperhatikan kondisi kehoranianya, sesuai agama yang mereka anut. Sarana yang berkaitan dapat dilihat pada tabel berikut ini.

Tabel 3. Jumlah Sarana Peribadatan di Desa Tateli Dua

\begin{tabular}{|c|l|c|}
\hline No. & \multicolumn{1}{|c|}{ Sarana Peribadatan } & Jumlah \\
\hline 1. & Mesjid & 1 \\
\hline 2. & Gereja Masehi Injli Di Minahasa & 1 \\
\hline 3. & Gereja Pantekosta & 1 \\
\hline \multicolumn{2}{|c|}{ Jumlah Total } & 3 \\
\hline
\end{tabular}

Sumber: Hasil Pengolahan Data Primer, 2018

Hasil pengamatan ternyata masyarakat Desa Tateli Dua tidak membeda bedakan agama, walaupun agama yang mereka anut berbeda satu dengan yang lainnya. Di daerah minahasa sudah terbentuk suatu wadah atau lembaga keagamaan yang disebut Badan Kerja Sama Antar Umat Beragama (BKSAUA) hal inilah yang mendasari masyarakat di desa ini lebih khusus nelayan responden di mana kondisi keagamaan mereka sangat mempedulikan satu dengan yang lain serta bergotong royong membangun kebersamaan dan saling menghargai, sehingga selalu tercipta kondisi yang baik dalam pergaulan masyarakat.

\section{$\underline{\text { Umur }}$}

Namun, usia yang relatif muda tidak menjamin mampu bekerja secara optimalkarena belum terampil dalam mengembangkan alat tangkap dan berpengetahuan untuk mengetahui daerah penangkapan ikan. Umur nelayan responden yang di Desa Tateli Dua dapat dilihat pada tabel berikut ini.
Tabel 4.Jumlah Responden Berdasarkan Klasifikasi Umur

\begin{tabular}{|c|c|c|c|}
\hline No. & Umur & Jumlah & $\begin{array}{c}\text { Persentase } \\
(\%)\end{array}$ \\
\hline 1. & $19-30$ & 7 & 35 \\
\hline 2. & $31-40$ & 2 & 10 \\
\hline 3. & $41-50$ & 6 & 30 \\
\hline 4. & $50-64$ & 5 & 25 \\
\hline \multicolumn{2}{|c|}{ Jumlah } & 20 & 100 \\
\hline
\end{tabular}

Sumber : Hasil pengolahan Data Primer, 2018

Umur tidak menjadi halangan bagi masyarakat untuk bekerja memenuhi kebutuhan setiap hari, dari usia muda sampai yang usia lanjut sudah dapat mengambil bagian dalam kerja perorangan atau dalam satu kelompok. Hasil penelitian $25 \%$ berumur 50 - 64 tahun masih bekerja karena dianggap sebagai umur produktif. Gambaran umur nelayan di Desa Tateli Dua $100 \%$ tergolong umur produktif karena, menurut Badan Pusat Statistik, mereka yang termasuk dalam golongan usia 15-64 tahun termasuk dalam usia produktif tenaga kerja.

\section{Kesehatan}

Kesehatan merupakan salah satu aspek sosial yang perlu diteliti bagi mereka yang berprofesi sebagai nelayan, di Desa Tateli Dua dari data 20 responden yang ada diketahui bahwa angka kesehatan penduduk terbilang baik, karena jarang mengalami kondisi kesehatan yang serius. Biasanya yang terjadi pada masyarakat nelayan yang dijadikan responden kebanyakanhanya mengalami sakit demam, saki lambung dan panas. Menurut masyarakat nelayan didesa ini, sakit yang diderita kebanyakan terjadi pada saat pulang melaut dan cuaca yang tidak bersahabat.Pada saat sakit panas atau demam biasanya mereka langsung ke Puskesmas terdekat untuk mengobati sakit yang diderita.Ada juga masyarakat nelayan yang mengobati sakitnya 
dengan obat-obat tradisional yang dipercaya mampu untuk mengatasi sakit tersebut.Responden yang pernah sakit dan penyakit yang diderita dapat dilihat pada Tabel 05 berikut ini.

Tabel 5. Jumlah Responden Berdasarkan Penyakit yang Dialami

\begin{tabular}{|c|l|c|c|}
\hline No. & \multicolumn{1}{|c|}{ Jenis Sakit } & Jumlah & $\begin{array}{c}\text { Persentase } \\
(\%)\end{array}$ \\
\hline 1. & Panas dan Demam & 11 & 55 \\
\hline 2. & Sakit lambung & 3 & 15 \\
\hline 3. & Flu dan batuk & 2 & 10 \\
\hline 4. & Prostat & 1 & 5 \\
\hline 5. & Paru-paru & 1 & 5 \\
\hline 6. & Tidak pernah sakit & 2 & 10 \\
\hline \multicolumn{2}{|c|}{ Jumlah } & 20 & 100 \\
\hline
\end{tabular}

Sumber : Hasil Pengolahan Data Primer, 2018

Responden yang mengalami sakit prostat berjumlah 1 orang atau 5\% dan responden yang mengalami sakit paru-paruberjumlah 1 orang atau $5 \%$ juga. Hasil wawancara mengapa dua respnden mengalami sakit prostat dan paru-paru ternyata mereka adalah responden yang sering sekali bekerja tanpa mengingat waktu dan terus bekerja keras serta pekerjaan yang dikerjakan banyak. Hasil penelitian untuk aspek kesehatan dari nelayan responden pada umumnya baik karena tidak mengalami sakit yang berat dan berkepanjangan.

\section{Tanggungan Keluarga}

Banyaknya jumlah anggota keluarga (1 - 6 orang) akan mempengaruhi tinggi rendahnya pendapatan per kapita dan besarnya konsumsi keluarga. Oleh karena itu, jumlah anggota keluarga atau besar keluarga akan memberi dorongan bagi rumah tangga bersangkutan untuk lebih banyak menggali sumber pendapatan lainnya. Dengan demikian, kemampuan melihat ke depan dengan mengadakan perencanaan biaya dipengaruhi oleh tingkat sosial ekonomi penduduk dan semakin bayak anggota rumah tangga cenderung semakin sulit merencanakan biaya (Surroyo, 2017).

Besarnya beban tanggungan keluarga pada setiap responden yang berjumlah 20 orang nelayan yang ada di Desa Tateli Dua akan berpengaruh terhadap tingkat kebutuhan dan kesejahteraan mereka, semakin banyak tanggungan keluarga maka semakin banyak pula kebutuhan rumah tangga yang harus dipenuhi. Dan jika pendapatan dari profesi sebagai nelayan tidak mampu mencukupi kebutuhan maka hal ini akan berdampak pada masalah kesejahteraan dalam keluarga. Di bawah ini dapat dilihat tanggungan keluarga yang terdapat pada nelayan Desa Tateli Dua yang menjadi responden.

Tabel 6. Jumlah Responden Berdasarkan Tanggungan Keluarga

\begin{tabular}{|c|c|c|c|c|}
\hline No. & Jumlah KK & $\begin{array}{c}\text { Jumlah } \\
\text { Tanggungan }\end{array}$ & Jumlah & $\%$ \\
\hline 1. & 2 & 2 & 4 & 10 \\
\hline 2. & 7 & 3 & 21 & 15 \\
\hline 3. & 5 & 4 & 20 & 20 \\
\hline 4. & 3 & 5 & 15 & 25 \\
\hline 5. & 3 & 6 & 18 & 30 \\
\hline Total & 20 & 20 & 78 & 100 \\
\hline
\end{tabular}

Sumber : Hasil Pengolahan Data Primer, 2018

Berdasarkan hasil penelitian yang paling banyak tanggungan dalam keluarga untuk $30 \%$ ada $3 \mathrm{KK}$ dan yang sedikit 10\% ada 2 KK. Menurut responden menjadi kepala keluarga tentu harus bekerja keras untuk memenuhi kebutuhan keluarganya.Pada saat cuaca tidak bersahabat untuk melaut tentu saja mereka selalu kehilangan akal untuk memenuhi kebutuhan rumah tangga mereka.

\section{Perumahan}

Kondisi rumah penduduk nelayan Desa Tateli Dua masih tergolong sangat sederhana.Hanya ada beberapa 
penduduk saja yang memiliki kondisi rumah yang layak tinggal seperti rumah permanen.Rata-rata bangunan rumah hanya menggunakan tripleks sebagai dinding rumah.Keadaan rumah seperti itu kebanyakan berada di jaga $\mathrm{V}$ karena berdasarkan jumlah alamat penduduk sebagian besar nelayan bertempat tinggal di wilayah tersebut.Perlu diketahui bahwa sebagian responden berpenduduk di jaga $\mathrm{V}$ dan yang paling dekat dengan pesisir pantai.Perlu diketahui juga berdasarkan pernyataan penduduk setempat bahwa tanah yang ditempati tersebut adalah tanah yang ada di jaga $V$ khususnya wilayah yang paling dekat dengan pantai, bahwa tanah itu milik Dinas Perikanan dan Kelautan.Tipe rumah respondendapat dilihat pada Tabel 7.

Tabel 7. Jumlah responden Berdasarkan Kepemilikan Rumah

\begin{tabular}{|c|l|c|c|}
\hline No. & \multicolumn{1}{|c|}{ Jenis Rumah } & Jumlah & $\%$ \\
\hline 1. & Permanen & 3 & 15 \\
\hline 2. & Semi permanen & 10 & 50 \\
\hline 3. & Gubuk & 6 & 30 \\
\hline 4. & Papan & 1 & 5 \\
\hline \multicolumn{2}{|c|}{ Jumlah } & 20 & 100 \\
\hline
\end{tabular}

Sumber : Hasil pengolahan Data Primer, 2018

Berdasarkan hasil penelitian didapatkan responden yang paling banyak mempunya rumah semi permanen ada 10 orang atau $50 \%$ dan yang paling sedikit ada rumah papan 1 orang atau $5 \%$. Masyarakat nelayan yang tinggal di kawasan milik Dinas Perikanan dan Kelautan ada $16 \mathrm{KK}$ termasuk di lingkungan jaga $\mathrm{V}$ dan $4 \mathrm{KK}$ di antaranya tinggal di lingkungan jaga II dan III. Hasil penelitian menggambarkan bahwa untuk aspek perumahan nelayan responden di Desa Tateli Dua dapat dikatakana sudah baik karena $65 \%$ rumah mereka sudah semi permanen bahkan ada yang permanen.

\section{Kondisi Ekonomi Nelayan Modal}

Modal yang digunakan pada produksi nelayan terdiri atas biaya perawatan dan biaya pengeluaran produksi. Semakin besar modal yang digunakan, maka akan semakin besar pula hasil produksi nelayan yang didapat (Rahman, 2016). Modal usaha yang dikeluarkan nelayan di Desa Tateli Dua dalam menjalankan dan mengembangkan usahanya dapat pada Tabel berikut ini

Tabel 8. Jumlah Responden Berdasarkan Modal

\begin{tabular}{|c|c|c|c|}
\hline No. & Modal Usaha & Jumlah & $\begin{array}{c}\text { Persentase } \\
(\%)\end{array}$ \\
\hline 1. & Modal sendiri & 19 & 95 \\
\hline 2. & Bantuan Pemerintah & 1 & 5 \\
\hline \multicolumn{2}{|c|}{ Jumlah } & 20 & 100 \\
\hline
\end{tabular}

Sumber : Hasil Pengolahan Data Primer, 2018

Pada Tabel 08 menggambarkan bahwa masyarakat nelayan yang menjadi responden mempunyai modal usaha terdiri dari; modal usaha sendiri terdapat 19 orang (95\%) dengan jumlah biaya yang dikeluarkan untuk modal tersebut sebesar Rp 2.000.000 - Rp 4.000.000. Sedangkan modal bantuan pemerintah terdapat hanya 1 orang saja karena nelayan tersebut memasukan proposal ke Dinas Kelautan dan Perikanan Provinsi Sulawesi Utara dan hasilnya bukan berupa uang tunai melainkan jenis bantuan berupa motor katinting 6,5 PK dan perahu pelang yang berukuran panjang 3 meter, lebar $60 \mathrm{~cm}$ dan kedalam perahu pelang $35 \mathrm{~cm}$.

\section{Pemasaran}

Hasil tangkapan yang didapat oleh responden kemudian dipasarkan ke berbagai tempat, dapat dilihat pada Tabel 09 berikut ini. 
Tabel 9. Jumlah Responden Berdasarkan Jenis Pemasaran

\begin{tabular}{|c|l|c|c|}
\hline No. & \multicolumn{1}{|c|}{ Jenis pemasaran } & Jumlah & $\%$ \\
\hline 1. & Ke masyarakat desa & 3 & 15 \\
\hline 2. & Perantara/ pengecer & 3 & 15 \\
\hline 3. & Pasar Tradisional & 13 & 65 \\
\hline 4. & Restoran & 1 & 5 \\
\hline \multicolumn{2}{|c|}{ Jumlah } & 20 & 100 \\
\hline
\end{tabular}

Sumber : Hasil Pengolahan Data Primer, 2018

Hasil penelitian menunjukan ada $65 \%$ dari responden memasarkan hasil tangkapan ikan ke pasar tradisional seperti pasar tradisional Malalayang dan pasar tradisional Bahu, dengan alasan selain dekat tempat pemukiman juga tidak terlalu banyak biaya yang perlu dikeluarkan dalam membawa hasil tangkapan untuk dijual dan 1 nelayan atau $5 \%$ menjual hasil tangkapan ke Restoran Mawar yang berada di Desa

Tabel 10.Tingkat Pendapatan Nelayan dan Pendapatan Sambilan Responden per Bulan

\begin{tabular}{|c|l|c|c|}
\hline No. & \multicolumn{1}{|c|}{ Nelayan } & $\begin{array}{c}\text { Pendapatan Pokok } \\
\text { (Rp) }\end{array}$ & $\begin{array}{c}\text { Pendapatan Sambilan } \\
\text { (Rp) }\end{array}$ \\
\hline 1. & Sahril Bilaku & $500.000-1.000 .000$ & 500.000 \\
\hline 2. & Rahman Husen & $500.000-1.000 .000$ & 500.000 \\
\hline 3. & Arsap Ratumbolu & $500.000-1.000 .000$ & 500.000 \\
\hline 4. & Shalu Tinjotu & $500.000-1.000 .000$ & 500.000 \\
\hline 5. & Revon Damir & $500.000-1.000 .000$ & 500.000 \\
\hline 6. & Muharjin Baba & $500.000-1.000 .000$ & 500.000 \\
\hline 7. & Irwan orban & $500.000-1.000 .000$ & 500.000 \\
\hline 8. & Salaudin Saibulan & $500.000-1.000 .000$ & 500.000 \\
\hline 9. & Anwar Tangona & $500.000-1.000 .000$ & 500.000 \\
\hline 10. & Abdul sibula & $500.000-1.000 .000$ & 500.000 \\
\hline 11. & Alfan Mujimu & $1.000 .000-1.500 .000$ & 500.000 \\
\hline 12. & Addul R. Salum & $1.000 .000-1.500 .000$ & 500.000 \\
\hline 13. & Deni Hasan & $1.000 .000-1.500 .000$ & 500.000 \\
\hline 14. & Jendri Ahmat & $1.000 .000-1.500 .000$ & 500.000 \\
\hline 15. & Tuamonang Hasibuang & $1.000 .000-1.500 .000$ & 500.000 \\
\hline 16. & Veky Pandey & $1.000 .000-1.500 .000$ & 500.000 \\
\hline 17. & Nyong Hontong & $1.000 .000-1.500 .000$ & 500.000 \\
\hline 18. & Manfut Mujimu & $2.000 .000-2.500 .000$ & 500.000 \\
\hline 19. & Samsudin saibula & $2.000 .000-2.500 .000$ & 1.000 .000 \\
\hline 20. & Aten Ismail & $2.000 .000-2.500 .000$ & 1.000 .000 \\
\hline S. & & \\
\hline
\end{tabular}

Sumber : Hasil pengolahan Data Primer, November 2018

\section{Berdasarkan hasil penelitian} pada Tabel 10 menunjukan bahwa pendapatan nelayan yang paling tinggi pendapatan pokok per bulannya berkisar Rp 500.000 - Rp 1.000.000/bulan berjumlah 10 orang atau $50 \%$. Untuk pendapatan pokok yang berkisar $\mathrm{Rp}$
Tateli dua, karena sudah menjadi langganan sesuai dengan jenis ikan yang diperlukan oleh restoran tersebut.

\section{Tingkat Pendapatan}

Nelayan yang berada di Desa Tateli Dua umumnya adalah nelayan tradisional yang usaha penangkapannnya masih menggunakan perahu dan alat tangkap tradisional.Selain itu jangkauan wilayah operasi penangkapan para nelayan di Desa Tateli Dua hanya di sekitar perairan teluk Manado saja.Rincian tingkat pendapatan nelayan perbulannya di Desa Tateli Dua disajikan pada Tabel 10 di bawah ini. 
memuaskan tetapi ada sebagian nelayan yaitu $50 \%$ masih kurang karena hanya memiliki alat penangkapan yang masih tradisional selain itu keterbatasan operasi penangkapan serta jangkauan wilayah operasi penangkapan yang lebih pendek dibandingkan dengan nelayan yang memiliki peralatan lebih modern karena mereka memiliki kapal motor.

Pendapatan dari pekerjaan sambilan ini didapati 18 orang nelayan mempunyai pendapatan Rp $500.000 /$ bulan, hasil ini mereka peroleh dari bekerja sebagai buruh bangunan, petani kangkung dan pengobat tradisinal.

\section{Pekerjaan Sambilan Responden}

Berikut ini pekerjaaan sambilan seperti buruh tani kangkung, buruh dan juga sebagai tukang bangunan, sebagian besar pekerjaan sambilan nelayan adalah sebagai buruh bangunan dan petani kangkung, ini karena di Desa Tateli Dua terdapat banyak usaha pertanian tanaman kangkung yang luas penggunaan lahannya mencapai 20 ha.
Tabel 11. Jumlah Responden Berdasarkan Pekerjaan Sambilan

\begin{tabular}{|c|l|c|c|}
\hline No. & Pekerjaan Sambilan & Jumlah & $\%$ \\
\hline 1. & Tukang bangunan & 10 & 50 \\
\hline 2. & Petani kangkung & 9 & 45 \\
\hline 3. & Pengobat tradisional & 1 & 5 \\
\hline \multicolumn{2}{|c|}{ Jumlah } & 20 & 100 \\
\hline
\end{tabular}

Sumber : Hasil Pengolahan Data Primer, 2018

Hasil penelitian didapatkan yang paling banyak dilakukan pekerjaan sambilan adalah tukang bangunan sebanyak 10 orang atau $50 \%$. Karena banyak pembangunan yang dilakukan di desa tersebut seperti pembangunan rumah warga, warung-warung dll.Pekerjaan sambilan pengobat tradisional ada 1 orang atau 5\% pekerjaan ini adalah untuk memenuhi kebutuhan sehari-hari mereka.

\section{Tingkat Pengeluaran}

Profesi sebagai nelayan sangatlah tidak gampang karena tuntutan biaya pengeluaran yang besar.Diketahui pada waktu penelitian data dari 20 responden bahwa pengeluaran per bulan untuk satu keluarga rata-rata berjumlah $\mathrm{Rp} 500.000$ - Rp 1.000.000 per bulan.Pengeluaran responden dalam satu bulan dapat dilihat pada Tabel 12 berikut ini.

Tabel 12.Jumlah Responden Berdasarkan Tingkat Pengeluaran

\begin{tabular}{|c|c|c|c|c|c|c|c|c|}
\hline \multirow{2}{*}{ No. } & \multirow{2}{*}{ Nama Responden } & & 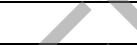 & \multicolumn{4}{|c|}{ Tingkat Pengeluaran (Rp) } & \multirow{2}{*}{ Total (Rp) } \\
\hline & & Makanan & Pakaian & Perumahan & Pendidikan & Kesehatan & Lain-lain & \\
\hline 1. & Sahril Bilaku & 90.000 & 90.000 & 60.000 & 80.000 & 50.000 & 130.000 & 500.000 \\
\hline 2. & Rahman Husen & 60.000 & 80.000 & 30.000 & 50.000 & 35.000 & 245.000 & 500.000 \\
\hline 3. & Arsap Ratumbolu & 480.000 & 300.000 & 250.000 & 280.000 & 71.000 & 119.000 & 1.500 .000 \\
\hline 4. & Shalu Tinjotu & 50.000 & 63.000 & 80.000 & 40.000 & 35.000 & 232.000 & 500.000 \\
\hline 5. & Revon Damir & 70.000 & 67.000 & 55.000 & 59.000 & 30.000 & 219.000 & 500.000 \\
\hline 6. & Muharjin Baba & 79.000 & 50.000 & 60.000 & 50.000 & 35.000 & 226.000 & 500.000 \\
\hline 7. & Irwan orban & 82.000 & 68.000 & 80.000 & 55.000 & 32.000 & 183.000 & 500.000 \\
\hline 8. & Salaudin Saibulan & 60.000 & 50.000 & 65.000 & 40.000 & 30.000 & 255.000 & 500.000 \\
\hline 9. & Anwar Tangona & 350.000 & 200.000 & 120.000 & 85.000 & 70.000 & 175.000 & 1.000 .000 \\
\hline 10. & Abdul sibula & 300.000 & 200.000 & 100.000 & 80.000 & 35.000 & 285.000 & 1.000 .000 \\
\hline 11. & Alfan Mujimu & 420.000 & 200.000 & 120.000 & 70.000 & 60.000 & 130.000 & 1.000 .000 \\
\hline 12. & Addul R. Salum & 400.000 & 140.000 & 200.000 & 30.000 & 30.000 & 200.000 & 1.000 .000 \\
\hline 13. & Deni Hasan & 200.000 & 210.000 & 120.000 & 79.000 & 30.000 & 361.000 & 1.000 .000 \\
\hline 14. & Jendri Ahmat & 345.000 & 150.000 & 100.000 & 90.000 & 59.000 & 256.000 & 1.000 .000 \\
\hline 15. & Manfut Mujimu & 95.000 & 90.000 & 60.000 & 80.000 & 50.000 & 125.000 & 500.000 \\
\hline 16. & Veky Pandey & 60.000 & 80.000 & 30.000 & 50.000 & 34.000 & 246.000 & 500.000 \\
\hline 17. & Nyong Hontong & 79.000 & 50.000 & 60.000 & 50.000 & 35.000 & 226.000 & 500.000 \\
\hline
\end{tabular}




\begin{tabular}{|r|l|r|r|r|r|r|r|r|}
\hline \multirow{2}{*}{ No. } & \multirow{2}{*}{ Nama Responden } & \multicolumn{6}{|c|}{ Tingkat Pengeluaran (Rp) } & \multirow{2}{*}{ Total (Rp) } \\
\cline { 2 - 7 } & & Makanan & Pakaian & Perumahan & Pendidikan & Kesehatan & Lain-lain & \\
\hline 18. & Tuamonang H & 87.000 & 68.000 & 80.000 & 55.000 & 34.000 & 256.000 & 500.000 \\
\hline 19. & Samsudin saibula & 450.000 & 200.000 & 120.000 & 70.000 & 60.000 & 1.100 .000 & 2.000 .000 \\
\hline 20. & Aten Ismail & 430.000 & 200.000 & 120.000 & 70.000 & 60.000 & 120.000 & 1.000 .000 \\
\hline
\end{tabular}

Sumber : Hasil Pengolahan Data Primer, November 2018

\section{Pada Tabel 13 menunjukan} tingkat pengeluaran pada responden kadang melebih dari nilai pendapatan hasil tangkapan mereka untuk memenuhi kebutuhan keluarganya.Sebagian dari pengeluaran responden untuk membiayai kebutuhan rumah tangga dan sebagian lainya adalah untuk membiayai tagihan-tagihan listrik dan air.Membayar uang sekolah anaknya, membayar biaya kesehatan dan membayar kebutuhan sehari-hari. Biaya pengeluaran responden paling banyak adalah 12 orang sekitar $\mathrm{Rp}$ 500.000 ,- per bulan dan yang paling sedikit 2 orang atau $10 \%$ sekitar Rp 1.500.000,- - Rp 2.000.000,- per bulan.

\section{KESIMPULAN}

Berdasarkan hasil penelitian maka dapat simpulkan bahwa kondisi sosial ekonomi masyarakat nelayan di Desa Tateli Dua Kecamatan Mandolang sudah cukup baik, ini terlihat dari kondisi perumahan tempat tinggal mereka yang sudah baik dan tingkat pendapatan yang cukup memadai.

\section{DAFTAR PUSTAKA}

Abdullah, F., 2003. Dasar-Dasar Manajemen Keuangan. Edisi Pertama. Malang: Universitas Muhammadiyah.

Abdullah, F., 2003. Manajemen Perbankan. Edisi Revisi. Penerbit UMM. Malang.

Abdulsyani. 1994. Sosiologi Skematika, Teori dan Terapan. Jakarta: Bumi Aksara.

Abdurahman, Fathoni, 2006. Metodologi Penelitiandan Teknik Penyusunan Skripsi. Jakarta: PT. Rineka Cipta.

Al Barry, M. Dahlan, 2001. Kamus IImiyah Populer. Yogyakarta: Arkola Surabaya.
Basrowi dan Siti Juariyah. 2010. Analisis Kondisi Sosial Ekonomi dan Tingkat Pendidikan Masyarakat Desa Srigading, Kecamatan Labuhan Maringgai, Kabupaten Lampung Timur. Jurnal Ekonomi dan Pendidikan. Vol. 7 No. 1 April 2010.

Dahlan Siamat. 2001.Manajemen Lembaga Keuangan. Edisi Ketiga, Fakultas Ekonomi Indonesia, Jakarta.

Daradjat Zakiah. 2005. Metodik Khusus Pengajaran Agama Islam. Jakarta: Bumi Akasara.

Dien, Ch. 2004.Penelitian Sosial Ekonomi Masyarakat Nelayan di Pantai Utara dan Selatan Kabupatrn Bolaang Mongondow. Tesis, Pascasarjana Universitas Sam Ratulangi, Manado.

Eko Wahyu Tyas, D. 2008. Penerapan Metode Association Rules Menggunakan Algoritma Apriori Untuk Analisa Pola Data Hasil Tangkapan Ikan.

Fakultas Kesahatan Masyarakat. 2006. Resiko Kesehatan Para Nelayan. Universitas Airlangga. Kabupaten Lombok Timur, Nusa Tenggara Barat.

Hamdani. 2013. Strategi Belajar Mengajar. Bandung: CV. Pustaka Setia.

Hansen dan Mowen. 2011. Buku I Management Accounting. Edisi 7, Salemba Empa, Jakarta.

Kotler, Philip. 2001. Manajemen Pemasaran: Analisis, Perencanaan, Implementasi dan Kontrol. Jakarta: PT. Prehallindo.

Kotler, Philip. 2002, Manajemen Pemasaran. Jilid 1, Edisi Milenium, Jakarta, Prehallindo.

Kusnadi. 2004. Mengatasi Kemiskinan Nelayan Jawa Timur: Pendekatan Terintegrasi, Bagaimana Harus Memulai?. Dalam Kusnadi(penyunting), Polemik Kemiskinan Nelayan, Yogyakarta: Pembaharuan.

Lewis, B.K. 2010. Social Media and Strategic Communication: Attitudes and Perceptions Among College Student. International Journal of Public Relation Society of America.

Manoppo. 2013. Mobilitas dan Alih Status Nelayan Skala Kecil di Provinsi Sulawesi Utara. Sekolah Pascasarjana Institut Pertanian. Bogor. https:// anzdor.com/ mobilitas - dan - ahli - status nelayan - skala - kecil - di - provinsi - Sulawesi utara- html. 
Melly G. Tan. 2000. Prosedur Penelitian Suatu Pendekatan Praktek. Yogyakarta.PT. Rineka Cipta.

Moleong. 2005. Metodologi Penelitian Kualitatif. Bandung: Remaja Rosdakarya.

Muflikhati, I., dkk. 2010. Kondisi Sosial Ekonomi dan Tingkat Kesejahteraan Keluarga Kasus di Wilayah Pesisir Jawa Barat. Jurnal IImu Keluarga. \& Konsumsi,Volume 3, No 1, 1-10.

Mulyadi. 2010. Sistem Akuntansi. Salemba Empat.http://k13umby2015. blogspot.com/2016/06/sistem-penerimaan-danpengeluaran-kas.html.

Nawawi, Ismail. 2014. Manajemen Perubahan: Teori dan Aplikasi pada Organisasi Publik dan Bisnis. Bogor: Ghalia Indonesia.

Notoatmodjo, S. 2007. Promosi Kesehatan dan IImu Perilaku. Jakarta: Rineka Cipta.

Rosyidi, Suherman. 2011. Pengantar Ekonomi. Jakarta: Raja Gravindo Persada.

Samuelson, Nordhaus. 2003. IImu Mikroekonomi. Jakarta: PT. Global Media. Edukasi.
Satria. 2002.Pengantar Sosiologi Masyarakat Pesisir. PT. Pustaka Cidesindo. Jakarta.

Sugiyono. 2013. Metodelogi Penelitian Kuantitatif, Kualitatif dan R\&D. (Bandung: ALFABETA).

Supardi, M.D. 2006.Metodologi Penelitian. Mataram: Yayasan Cerdas Press.

Bandung: Alfabeta.

Suroyya, A.N. 2017. Analisis Ekonomi Rumah Tangga Nelayan Pada Alat Tangkap Gill Net di PPP Morodemak, Kabupaten Demak. Journal of Fisheries Resources Utilization Management and Technology Volume 6, Nomor 4, Tahun 2017, HIm 30-39 Online di: http://www.ejournals1.undip.ac.id/index.php/ifrumt.

Sumarsono, Sonny. 2003. Ekonomi Manajemen Sumber Daya Manusia dan Ketenagakerjaan. Yogyakarta : Graha IImu.

Sukirno, 2006. MakroEkonomi: Teori Pengantar. Penerbit PT. Raja Grafindo Persada, Jakarta.

Taringan, H. Guntur. 2009. PengkajianPragmatik. Bandung: Angkasa. 